\title{
Notas sobre Los españoles en Rosario (1934): \\ Una vindicación republicana de la inmigración española en la Argentina
}

\author{
por \\ Xosé M. Núñez Seixas \\ Ludwig-Maximilians Universität, Múnich
}

En 1934 vio la luz en la ciudad argentina de Rosario de Santa Fe un opúsculo de divulgación histórica firmado por dos desconocidos periodistas y literatos españoles, Eduardo Miragaya y Francisco Solanes, titulado Los españoles en Rosario de Santa Fe. Su influencia en el progreso de la ciudad (Rosario: Editorial La Cervantina, 1934, 243 pp.), con prólogo del diplomático y cónsul español en Rosario desde el año anterior Gonzalo Diéguez Redondo (1893-1955). No sabemos prácticamente nada de los autores, que podemos presuponer que eran dos de tantos inmigrantes españoles de cierta formación arribados a la Argentina en el primer tercio del siglo XX, como parte de la inmigración más o menos cualificada o de «bachilleres» que esperaba hacer carrera en la República Austral en la prensa y la tribuna pública. Igualmente, su obra ha pasado casi desapercibida para buena parte de la historiografía migratoria argentina y española, oscurecida en parte por el mayor peso de la colonia española de Buenos Aires y su rica vida cultural. No obstante, como se propone en las páginas que siguen, Los españoles en Rosario de Santa $\mathrm{Fe}$ constituye un buen ejemplo de la moderada reivindicación del papel de España en América elaborada por la intelligentsia republicana hispánica en la Argentina, y de la reorientación incipiente del discurso hispanoamericanista, en clave liberal, que fue promovida y alentada por la política exterior de la II República española durante su breve existencia. 


\section{La inmigración española en Rosario de Santa Fe}

La ciudad de Rosario, al igual que la provincia de Santa Fe, no se quedó al margen del fenómeno de la inmigración masiva que, procedente de España, se dirigió a la República Argentina en el período comprendido entre 1880 y 1930. Como es bien conocido, alrededor de dos millones de ciudadanos españoles llegaron en ese período a las orillas del Plata, y de ellos alrededor de un 60 por ciento (1,2 millones) se estableció definitivamente en el país. Eran el segundo grupo en importancia, después de los italianos (1,5 millones). Según las entradas de pasajeros de ultramar entre 1878 y 1927, un 46,2 por ciento de los ingresos correspondió a los inmigrantes italianos, seguidos de un 32,88 por ciento de españoles, y un 20,9 por ciento de muy diversas procedencias. El punto álgido de las llegadas de inmigrantes desde España se registró en las dos primeras décadas del siglo $\mathrm{XX}$, cuando su número superó en términos absolutos al de los transalpinos. Desde mediados del XIX, la presencia de vascos peninsulares de ciudadanía española también había sido característica de algunas zonas rurales, así como de los núcleos cercanos a Buenos Aires y de las localidades del interior de la provincia bonaerense. A ellos se unieron algunos gallegos y asturianos, ya presentes en proporción apreciable desde los últimos tiempos del período colonial ${ }^{1}$.

La inmigración española se concentró de modo especial en los grandes núcleos urbanos del litoral, tanto en la provincia de Buenos Aires como en Santa Fe, y en menor medida en provincias como Córdoba y Mendoza ${ }^{2}$. En 1914, un 73 por ciento de los inmigrantes españoles estaban radicados en áreas urbanas, una proporción mayor que en otros grupos inmigrantes. Un 10 por ciento de los mismos se ubicó en la provincia de Santa Fe, y porcentajes menores se asentaron en las de Córdoba y Mendoza. Igualmente, el colectivo español demostró una mayor propensión que otras comunidades inmigrantes a concentrarse en las actividades terciarias urbanas, aunque de modo más o menos acusado según las procedencias regionales. Gallegos, asturianos y montañeses mostraban una mayor preferencia por el comercio y los servicios

\footnotetext{
1 Para una visión general acerca de la inmigración en la Argentina, ver Devoto, 2003.

${ }^{2}$ Para una visión general de la inmigración española en Argentina, Sánchez Alonso, 1992. Fernández y Moya, 1999. Moya, 2004. Sobre las diferentes colectividades ibéricas, particularmente sobre los gallegos, los vascos y los catalanes, así como sobre otros colectivos menores (zamoranos, valencianos, asturianos, etcétera), y sobre ciudades concretas, existen igualmente varios trabajos, que excusamos de citar aquí de modo exhaustivo. Como principales ejemplos significativos, ver Da Orden, 2005. De Cristóforis, 2008; 2009. Farías, 2007. De Cristóforis y Fernández, 2008. Irianni, 2010. Jofre Cabello, 2001. Núñez Seixas, 2001a. Vera de Flachs, 1996.
} 
que castellanos, leoneses, valencianos o andaluces, además de los vascos. Un alto porcentaje de los españoles se concentró en la ciudad de Buenos Aires, tendencia especialmente acusada entre el contingente territorial mayoritario de los mismos, los gallegos, que suponían alrededor del 50 por ciento del conjunto de los inmigrantes españoles en la capital.

La distribución por regiones de procedencia, empero, era más variada en las ciudades del litoral y del interior argentino, tanto en las de fundación reciente (caso de Mar del Plata o La Plata) como en las de mayor tradición desde el período tardocolonial, como Córdoba, Santa Fe y Rosario. En esta última, la actividad portuaria vinculada al modelo económico agroexportador, que convirtió a la ciudad en el principal puerto de salida de la producción cerealífera de la provincia de Santa Fe, atrajo además desde la década de 1890 a un alto número de inmigrantes españoles de las más diversas procedencias que, después de un tiempo empleados en el sector terciario, se trasladaron definitivamente a Buenos Aires.

Ciertamente, hubo en la provincia de Santa Fe contingentes apreciables de inmigrantes españoles que residían en el campo, dedicados a cultivar la tierra como arrendatarios o pequeños propietarios, además de desempeñarse como intermediarios comerciales e inversores en tierras. Como en otras zonas del interior argentino, diversos grupos de colonos agrícolas procedentes de un mismo lugar en España se ubicaron en localidades determinadas, a las que sus parientes y convecinos arribaban después a través de redes microsociales. Por poner un caso, así ocurrió con los naturales de la isla de Ibiza en la ciudad de Santa Fe y algunas poblaciones de los alrededores como Santo Tomé ${ }^{3}$. Varios de ellos fueron auténticos «pioneros», que acumularon grandes fortunas como propietarios de tierras e inversores en actividades inmobiliarias y agropecuarias.

Sin embargo, la preferencia de los inmigrantes ibéricos en Santa Fe fue claramente la ciudad de Rosario. Ésta se convirtió, aunque muy por detrás de la capital federal, en el segundo centro receptor de inmigrantes españoles de la Argentina en el período 1880-1930. En Rosario residían casi la mitad de los 84.648 españoles que habitaban en la provincia santafesina hacia 1914. De una magra población de 1.118 españoles en 1869, la ciudad del Paraná pasó a contar con 40.256 habitantes nacidos en España en 1914, y con 66.459 habitantes en 1926. Aunque en términos absolutos y relativos estuvieron bastante por detrás de los inmigrantes italianos, principal grupo migratorio en la urbe rosarina y anterior en su llegada, el aporte ibérico al fuerte crecimiento demográfico que registró la ciudad en el primer cuarto del siglo XX fue muy

\footnotetext{
${ }^{3}$ Jofre Cabello, 2001: 109-113.
} 
significativo, y aumentó además en proporción con el tiempo. Si en 1887 los españoles suponían el 6 por ciento de la población urbana de Rosario, y los italianos un 23 por ciento, en 1926 los primeros totalizaban un 16 por ciento de los rosarinos, por un 19,6 por ciento de transalpinos ${ }^{4}$.

Los inmigrantes españoles en Rosario se dedicaron a un abanico de actividades que era, considerado de forma genérica, muy similar al que les caracterizaba en Buenos Aires. Vinculados al sector comercial y terciario en general, habitaron en un principio los distritos céntricos, para instalarse después en los nuevos barrios industriales de la periferia, a medida que la expansión urbana de Rosario trajo aparejada una diversificación creciente de las actividades productivas, particularmente en la industria. Los españoles pasaron entonces a residir en barrios como Talleres del FCA, Aguas Corrientes y Barrio Refinería conforme avanzaba el siglo XX, empleándose en sectores como las actividades portuarias no cualificadas, la construcción de líneas férreas, la edificación residencial y las obras públicas. En 1906 el colectivo español de Rosario se caracterizaba por el predominio de trabajadores a jornal (42,5 por ciento), seguidos de empleados (21,5 por ciento) y comerciantes (17,5 por ciento).

Sin embargo, el colectivo español de Rosario también presentaba algunas peculiaridades respecto al modelo «canónico» y mejor conocido de Buenos Aires. Sobre todo, en lo relativo al peso dentro de la comunidad de las distintas procedencias regionales. Frente al claro predominio de los gallegos en la capital federal, equiparable o superior al 50 por ciento, apenas un 10-11 por ciento del colectivo español establecido en Rosario procedía de Galicia. Castellanos de la antigua región de Castilla la Vieja y leoneses constituyeron en Rosario el 23 por ciento del total español, mientras que los andaluces llegaban a representar en 1914 una cuarta parte del mismo. Había igualmente porcentajes importantes de asturianos y de españoles de otras procedencias, además de una presencia significativa de vascos y de catalanes, especialmente relevantes entre la élite comercial de la ciudad. Todos ellos conferían una fisonomía propia, pero polícroma en sus matices identitarios, al colectivo español. Dentro de cada grupo regional y hasta local se registraron especializaciones productivas concretas, determinadas a menudo por el éxito de los pioneros en un ramo determinado. De este modo, si los baleares progresaron en el sector de la panadería, los asturianos lo hicieron en el negocio de los bares, los almacenes y la distribución y venta de tabaco, y los gallegos ocuparon posiciones en los oficios relacionados con la carpintería de barcos, la descarga y tráfico de mercancías portuarias. Además, muchos inmigrantes que

${ }^{4}$ Para lo que sigue, ver la síntesis de Frid, 1999. Así como Lanciotti, 2003. Algunos datos en De Marco, 1988. 
se establecieron en el sector del comercio minorista en Buenos Aires habían pasado etapas de su periplo migratorio, de forma más o menos esporádica, en Rosario 5 . Finalmente, al igual que en otras ciudades, el colectivo español se caracterizó por una alta tasa de endogamia, que aumentó además entre 1900 y la segunda mitad del siglo XX gracias al aumento de la presencia de mujeres dentro del flujo inmigrante, si bien la exogamia de las féminas españolas era mayor entre 1900 y 1914 que la de las italianas, como parte de una estrategia de ascenso social destinada a desposar varones de mayor posición, en buena parte argentinos ${ }^{6}$.

\section{Algunos patriotas entre dos mundos: La élite española de Rosario}

A principios del siglo $\mathrm{XX}$, y como en otras ciudades argentinas, existía ya en Rosario una élite comercial y financiera de inmigrantes españoles bien consolidada, con base sobre todo en sectores como el comercio de comestibles, en particular cereales, y de importación. Varios de ellos llegaron a ocupar puestos importantes en los círculos económicos y financieros de la ciudad. Y estuvieron también, junto con algunos expatriados de ideas republicanas, detrás de las iniciativas para articular un tejido asociativo de la colectividad española en Rosario. Comerciantes y propietarios urbanos y rurales que dejaron impronta en la vida económica y social de la ciudad, como los gallegos José Piñeiro (i-1909) y Manuel y José Arijón (1852-?), el asturiano Angel García Fernández, o los catalanes Toribio Sánchez Beltrán de Guevara (i1928) y Miguel Montserrat, entre otros muchos, unieron sus esfuerzos a los de aquellos expatriados para representar los intereses de la comunidad española de Rosario, además de para crear una red de mediación entre esos mismos intereses, la imagen de la comunidad, las autoridades españolas y rosarinas, y el Estado argentino.

${ }^{5}$ Desde algunas zonas costeras gallegas -Rianxo o Betanzos, por ejemplo- se registró, de hecho, una emigración de carpinteros de ribera y otros oficios cualificados relacionados con la navegación fluvial y de altura hacia Rosario en la década de 1880, que distamos de conocer en profundidad. Sirva como muestra que dos tíos del máximo dirigente histórico del nacionalismo gallego Alfonso R. Castelao -él mismo residente en Argentina entre 1896 y 1900, así como, ya exiliado, entre 1940 y 1950-, Francisco y Juan Castelao Gemme, se establecieron en Rosario en aquella época y progresaron en el ramo de la carpintería. Para ejemplos de la circulación, aún poco conocida, de dependientes de comercio y comerciantes minoristas entre Rosario y Buenos Aires, ver Núñez Seixas y Soutelo, 2005: 99.

${ }^{6}$ Frid, 1994. 
La élite hispana de Rosario conformaba un tejido de amistades, redes sociales y lugares de sociabilidad en el que las ideas regeneracionistas para España y el republicanismo importado del Viejo Continente se combinaron de modo ecléctico con los nuevos estímulos que ofrecían diversas iniciativas de la política argentina, que iban desde el reformismo de Joaquín V. González, hasta el socialismo austral. Los empresarios e intelectuales reformistas españoles constituían así una suerte de red de notables con posiciones oscilantes entre el socialismo ilustrado de Juan B. Justo, el radicalismo y la reforma social, pero sin veleidades revolucionarias. Y en Rosario esas élites encontraron además unas posibilidades francas de ascenso social y de influencia política en el ámbito local y provincial, constituyendo un elemento fundamental de la nueva élite sociopolítica de las ciudades del interior argentino, más dispuesta a integrar elementos «advenedizos» que la élite criolla de Buenos Aires.

El más importante, y el precursor de todos ellos, fue sin duda Carlos Casado de Alisal (1833-1899), natural de Villada (Palencia) y marino de profesión, que había arribado a Rosario hacia 1857. Corredor de comercio, banquero que constituyó ya en 1874 el Banco Casado y empresario, destacó también como gran propietario agrario y promotor de varias colonias, que se extendieron al Gran Chaco paraguayo, así como del Ferrocarril Oeste Santafesino. Casado de Alisal fue asimismo uno de los grandes impulsores de la construcción del puerto de Rosario, además de, probablemente, uno de los notables españoles de mayor éxito empresarial en la Argentina de su época ${ }^{7}$. Su estela fue continuada por varios nombres más. El barcelonés Juan B. Quintana (1860-1914) se estableció en Rosario en 1889, donde desarrolló una brillante carrera empresarial como industrial y comerciante, siendo presidente en varias ocasiones de la Bolsa de Comercio y la Cámara Sindical. Aunque coqueteó en diversos momentos con el catalanismo, Quintana se comprometió desde 1898 con las manifestaciones patrióticas de la colectividad hispánica; también ostentó desde 1907 los cargos de vicecónsul y cónsul español en Rosario. Por su parte, Julián Daniel Infante (1863-1930), natural de Osorno (Palencia), había llegado en 1889 a la ciudad. Respondía perfectamente al perfil del expatriado peninsular de la época, pues aunque emigró voluntariamente a Argentina, lo hizo también por no encontrarse a gusto en la España de la Restauración, y buscaba nuevos horizontes para sus ideales. Se había comprometido con el pronunciamiento del general Villacampa en 1886, cuando Infante era aún un joven licenciado en Derecho. En Rosario trabajó al servicio de Casado de Alisal como administrador de sus bienes y negocios, y se labró un puesto en la política santafesina,

${ }^{7}$ Sobre la actividad empresarial y la faceta como latifundista de Casado de Alisal, ver Dalla Corte, 2009. Igualmente, De Marco, 1993. Ascolani, 1992. 
vinculado a la Liga del Sur, predecesora del Partido Demócrata Progresista; pero mantuvo también fuertes lazos con el radicalismo local. Gracias a ello desempeñó, a propuesta del primer gobierno radical de Santa Fe, el puesto de intendente municipal entre noviembre de 1912 y abril de 1913, período marcado en Rosario por la conflictividad obrera. Igualmente, Infante destacó como profesional de la abogacía y profesor vinculado al comercio, el Estado y la Universidad argentina. Pero nunca cejó en su compromiso con la causa del progreso y la República en España, tema al que dedicó varios opúsculos, además de promover la edición del órgano El Republicano.

Finalmente, cabe también citar nombres como los del médico y jurisconsulto catalán Juan Bialet i Massé (1846-1907), arribado a la Argentina hacia 1873, quien dedicó buena parte de su reflexión y actividad intelectual al campo del Derecho Laboral y el higienismo social, desde un compromiso político con el socialismo reformista, siendo un referente del movimiento obrero rosarino; el publicista y profesor madrileño Enrique Corona Martínez, aludido explícitamente por Miragaya y Solanes como «uno de tantos inmigrantes políticos, pero que en Rosario no abundaban»; o el periodista y abogado andaluz Serafín Álvarez Peral (1842-1925), arribado a la Argentina en 1873 después de una primera etapa en el país como expatriado, quien se estableció como juez en Rosario y destacó como periodista y propagandista del socialismo.

La élite española de Rosario pretendía, en líneas generales, «hacer patria» y defender el buen nombre de España, al mismo tiempo que contemplaba esa estrategia de mediación y representación como una parte inseparable de su ascenso social individual ${ }^{8}$. E interpretaba asimismo la plasmación de sus proyectos políticos en la Argentina como una sublimación de lo que también desearían aplicar en España, utilizando a los emigrados como trampolín y motor de la regeneración y reforma en el terruño. Era una suerte de "patriotismo ausente» que enjuiciaba el país, y sus regiones de origen, con ojos analíticamente críticos y sentimentalmente apasionados 9.

La expresión más temprana de la comunión entre élites económicas, necesidades objetivas de asistencia mutua, protección y recreo de los nuevos inmigrantes, y las inquietudes de la élite inmigrada de orientación reformista fue la constitución de varias sociedades españolas. La pionera fue la Asociación Española de Socorros Mutuos (AESM), la segunda más importante de América, que nació en junio de 1857 -seis meses antes que la de Buenos Aires-con

8 Para los perfiles biográficos, ver Duarte, 2010. Sánchez, 2005. Fernández y Dalla Corte, 1999. Tarcus, 2007: 15-17, 70-71. Biagini, 1995: 135-48. Sonzogni y Dalla Corte, 2002.

9 Sobre la cultura política de los expatriados republicanos españoles en la Argentina, ver Duarte, 1998; 2002. 
el concurso de un enviado de la AESM de Montevideo, el gaditano José $\mathrm{M}^{\mathrm{a}}$ Buyo. A principios de siglo, la AESM rosarina agrupaba 1.500 socios, el 12 por ciento de los residentes españoles en Rosario. El Club Español, fundado en 1882, agrupaba a la flor y nata de la colectividad española, al igual que su homónimo de Buenos Aires ${ }^{10}$. El Hospital Español esperó más tiempo a ver la luz, hasta 1912. Otras entidades de carácter más sectorial fueron el Patronato Español (1915) y la Cámara Oficial Española de Comercio, Industria y Navegación (1920), la delegación rosarina de la Institución Cultural Española, y una serie de agrupaciones regionales: el Centre Català (1902), el Centro Asturiano (1904), el Centro Navarro (1913), la Agrupación Andaluza (1915), el Centro Gallego (1915), el Centro Aragonés (1917), el Centro Castilla (1920), el Centro Riojano Español (1920) y el Centro Soriano (1922). También nacieron en Rosario algunas asociaciones microterritoriales, que fueron especialmente importante en el caso gallego, si bien varias de ellas se trasladaron después a Buenos Aires, ciudad donde el fenómeno adquirió proporciones masivas ${ }^{11}$. En 1904, finalmente, surgió en Rosario una filial de la Liga Republicana Española constituida un año antes en Buenos Aires, y que tendría continuidad años más tarde en el Centro Español de Unión Republicana (1930). Respondía a los impulsos tardíos del republicanismo español finisecular, fundiendo un mensaje regeneracionista en lo nacional, reformista avanzado en lo social y positivista en lo filosófico.

Fuera de ellos, cabe recordar que inmigrantes vascoespañoles y vascofranceses se agruparon en el centro Zazpirak Bat («siete en una»), fundado en 1912 a iniciativa de varios sacerdotes y algunos inmigrantes vascos de simpatías nacionalistas, y que tras diversas polémicas cayó definitivamente, a partir de 1923, bajo el control de una dirigencia afín al nacionalismo vasco. Razón ésta, además de su carácter vasco transfronterizo, por la que curiosamente no fue incluido dentro del elenco de sociedades «regionales» que consta en el apéndice de Los españoles en Rosario, y sí figura el Centro Navarro, constituido un año antes y, en parte, opuesto por mor de su españolismo antivasquista al Zazpirak Bat. Del mismo modo, el Centre Català experimentó un fuerte influjo del catalanismo durante la década de 1920. Y también a Rosario llegaron ecos del nacionalismo gallego, que sin embargo ganó muchos más adeptos

${ }^{10}$ Ver Fernández y Oliver, 2004

${ }_{11}$ Por ejemplo, la sociedad de los naturales de los municipios de Rois (A Coruña) y de O Saviñao (Lugo) en 1888 y 1892, respectivamente. O los naturales del ayuntamiento de Betanzos, que acabaron fundando la sociedad Hijos de Betanzos en Buenos Aires en 1905. Cf. Núñez Seixas, 2011. 
entre el entramado institucional de los inmigrantes galaicos en Buenos Aires, desde 1917-18 ${ }^{12}$.

\section{Los Españoles en Rosario de Santa $F_{E}$ : Una obra Vindicativa y MODERADAMENTE REPUBLICANA}

La colectividad española de Rosario, por tanto, era en la tercera década del siglo XX una de las más pujantes de la ciudad, contaba con líderes étnicos de reconocido prestigio que habían contribuido y seguían contribuyendo al progreso económico santafesino, y habían tejido vínculos importantes con los círculos del poder y la política locales, provinciales y nacionales. El advenimiento de la II ${ }^{a}$ República en España en abril de 1931 respondía, desde la distancia, a los ideales largo tiempo defendidos por la élite republicana inmigrante de Rosario, al menos si se contemplaba desde la distancia, si bien varios de ellos, como Daniel Infante, no vivieron lo bastante como para conocerla. La diplomacia del nuevo régimen republicano español tuvo la intención, no realizada plenamente por falta de tiempo y por la inestabilidad de los equipos ministeriales encargados de diseñar la política exterior, de dedicar una atención particular hacia América Latina. Buscaba superar los recelos de otras épocas y, al mismo tiempo, reinterpretar la significación y sentido de la huella española en el Nuevo Continente, y en la Argentina en particular, desde un punto de vista diferente al discurso hispanoamericanista mayoritario que había sido propiciado desde los sectores tradicionalistas y monárquicos de la antigua metrópoli. En ese propósito también colaboraba la incipiente renovación de los estudios históricos sobre Latinoamérica que tuvo lugar en España durante el período de la II República, deudora en parte del magisterio de Rafael Altamira ${ }^{13}$.

¿En qué podemos apreciar esa orientación? En el libro de Miragaya y Solanes son observables algunas orientaciones generales, dentro de un propósito genérico expresado en el deseo de «reivindicar el prestigio español». En primer lugar, el énfasis otorgado a la época colonial, y al papel de los conquistadores españoles en ese período, aparece en él muy matizado. Los conquistadores son reivindicados, de forma moderada y elíptica, como hombres

12 Para la difusión de los nacionalismos vasco, catalán y gallego entre los emigrantes, ver una visión comparativa en Núñez Seixas, 2001b. Sobre el caso específico del nacionalismo vasco en Rosario, Álvarez Gila, 2000.

13 Tabanera García, 1996. Marcilhacy, 2010. Sepúlveda, 2005: 296-98. Sobre el hispanoamericanismo historiográfico en este período, Bernabeu Albert, 2007. 
del pueblo, identificándolos implícitamente con colonos o pobladores. Una suerte de precursores avant la lettre del carácter de los emigrantes corrientes, paralelismo del que gustaba especialmente la publicística y la prensa étnica de los inmigrantes españoles, quienes eran presentados como personas que «llegaron hasta estas tierras que baña el Paraná [...] decididos a la pelea, al trabajo y a multiplicarse». No se pone el acento en sus hazañas militares, o en su contribución a la cristianización de los indígenas, como sí destacaba, con sus correspondientes nóminas de evangelizadores y misioneros, el discurso hispanoamericanista conservador. La principal aportación de esos conquistadores habría consistido en ser pobladores de las tierras americanas, y haber dado remoto origen a la ciudad de Rosario, desde los primeros asentamientos de 1527. Se pasa igualmente por encima de episodios históricos plagados de claroscuros y que no interesaban ni a españoles ni a argentinos, como el destino durante las primeras décadas del dominio español de las poblaciones indígenas, a las que veladamente se les supone poco amantes del trabajo y la civilización. Pero también se destaca, en clara oposición a la «Leyenda Negra» y basándose en historiadores argentinos hispanófilos como José León Suárez, que ni la situación de los indígenas era tan negativa desde el punto de vista jurídico durante la etapa colonia, ni sus condiciones de vida habían mejorado de modo particular tras la independencia argentina.

En segundo lugar, el énfasis en las aportaciones individuales se vincula claramente a un espacio cuya reivindicación también se postula. Los grandes hombres del pasado, como el docente de fines del siglo XVIII Pedro Tuella, son vistos en esta obra como poetas y civilizadores, a la par que como funcionarios de la Corona española y primeros historiadores de la ciudad, conscientes de la individualidad y especificidad local de Rosario. La primacía otorgada a la identidad local, el refugio en el ámbito de los espacios y ambientes próximos al lector y su vida cotidiana, al recordar los orígenes de los distintos barrios y del «progreso» rosarino, sirve a los autores para destacar el papel jugado en él por los colonizadores españoles durante la época colonial. Los avances materiales y del progreso se acompañaron de oficios varios, adelantos técnicos y establecimientos que fueron otorgando fisonomía urbana a Rosario. Toda distinción o matiz entre criollos y españoles resultaba así difuminada, gracias en buena parte al realce de la dimensión local, que actuaría de crisol inmejorable de españoles y nativos.

En tercer lugar, y como en todas las recreaciones de la presencia hispánica en la historia argentina escritas por miembros de las élites inmigrantes españolas, se plantea aquí el problema de cómo interpretar un período conflictivo en el que era necesario cuadrar el círculo. Había que presentar la aportación de los españoles al proceso de emancipación de la Corona española desde 
1808, sin acusarlos de antipatriotas (hispánicos o argentinos). Y urgía hacerlo sin contradecir en exceso las versiones canónicas de la historiografía nacionalista argentina del siglo XIX. La no siempre soterrada hispanofobia de esta última, que seguía vigente por lo demás entre amplios sectores del mundo intelectual argentino hasta la segunda década del siglo XX, aconsejaba por otro lado vindicar de modo positivo la contribución española al «progreso» argentino. El recurso, utilizado de modo profuso por los historiadores y publicistas españoles, consistió en primer lugar en destacar la movilización de los Tercios de peninsulares (gallegos, catalanes o vizcaínos) en la resistencia a las invasiones inglesas de 1806-07, lo que permitía afirmar la participación peninsular en una lucha común junto a los criollos frente a un invasor foráneo. Igualmente, el proceso de independencia es aquí contemplado como «emancipación», nunca como una separación de la patria de origen, y es presentado además como el resultado casi inesperado de una lucha conjunta de liberales criollos y peninsulares, primero como consecuencia del vacío de poder creado por la invasión de España por parte de los ejércitos napoleónicos en 1808, y más tarde como una respuesta a la reacción absolutista encarnada en la metrópoli por el rey Fernando VII desde 1814. De modo indirecto se venía así a sostener que había sido la Monarquía la que había contribuido a enajenar una parte de España de su seno, y que los primeros criollos no eran sino auténticos patriotas españoles liberales que recrearon una nueva España bajo nuevos principios ${ }^{14}$.

No es de extrañar, por lo tanto, que en la obra que aquí prologamos se destaque como un hito digno de mención la publicación del libro del ya aludido José León Suárez, Carácter de la Revolución Americana (Buenos Aires: Imprenta Suiza, 1917), edición que fue apoyada por una suscripción popular entre los españoles residentes en Rosario con el fin de adquirir ejemplares y aumentar así la tirada, concluyendo que «La guerra de la Independencia, más que lucha entablada entre oprimidos y opresores fue una guerra civil. Protesta contra el absolutismo de un Rey. Rebelión de españoles y criollos». Y también es significativo que no se mencionen por Miragaya y Solanes las movilizaciones nacionalistas protagonizadas por la colonia inmigrante en la Argentina a favor de la causa española durante el período 1895-98, en las que también había participado lo más granado de la élite hispánica de Rosario. Seguramente, por el hecho de que la causa de los insurrectos cubanos había disfrutado de gran predicamento entre la opinión pública argentina, y con motivo del conflicto se habían producido en todo el país austral enfrentamientos en plena calle entre manifestantes procubanos e inmigrantes españoles. La

${ }^{14}$ Núñez Seixas, 2002: 185-90. Sepúlveda, 2005: 225-41. 
Asociación Patriótica Española surgió entonces en Buenos Aires al calor del conflicto cubano, como exponente de un exaltado nacionalismo español en el que republicanos y monárquicos se daban la mano en la defensa de las últimas colonias americanas ${ }^{15}$. A pesar de que la Patriótica se erigió en un crisol de muchas de las redes sociales que estaban detrás de los proyectos empresariales y agrícolas de los grandes propietarios españoles ${ }^{16}$, su existencia es igualmente omitida en el repaso a las diversas instituciones españolas existentes en Rosario en el pasado y el presente. Un silencio sin duda elocuente, al igual que lo es la omisión de la repercusión entre la colonia española de la Guerra del Pacífico librada entre Bolivia, Chile, Ecuador y Perú por un lado y España por el otro (1864-1866), durante la cual también habían florecido las muestras de hispanofobia de la opinión pública argentina, al menos en otras ciudades del país ${ }^{17}$.

Los tópicos del hispanoamericanismo conservador son aquí, cuando menos, reformulados y matizados. De este modo, y aunque se obvia la discusión sobre el alcance del término "hispanoamericanismo», se sigue utilizando el vocablo «Raza» y se expresa la preferencia por la denominación «Día de la Raza» para designar la festividad del 12 de octubre. Pero la formulación de ese concepto no es de naturaleza biológica, al destacar la mezcla étnica de diferentes poblaciones que auspiciaron los españoles en América y la propia diversidad regional y etnocultural hispánica, sino que adquiere un matiz preferentemente histórico, cultural y «espiritual». Se alude a la raza como un «principio de armonía hispanoamericana, como recuerdo del pasado y como una afinidad esencial para pensar también en el futuro». Más adelante, al citar al escritor mexicano José de Vasconcelos, se recuerda también que la comunidad hispanoamericana constituiría un «imperio moral para un mundo que ha perdido el camino». En el fondo, resuena el eco en esas concepciones de José Ortega y Gasset y su definición de la nación como comunidad de destino, así como la idea, expresada en su momento por el historiador liberal Rafael Altamira, de que existía una civilización común que unía a españoles e hispanoamericanos ${ }^{18}$. Es igualmente significativo que se ponga tímidamente el acento en la orientación pacifista de la política exterior de la II República española como modelo de legitimación de un nuevo papel en el mundo his-

15 Romero, 2007.

16 Dalla Corte, 2009, para más detalles.

17 Ver algunos ejemplos en Núñez Seixas, 2002: 35-37.

18 Sepúlveda, 2005: 190-96; Valero Juan, 2003. Sobre el importante influjo de las ideas historiográficas de Altamira en la Argentina, en particular tras su viaje al país en 1911, ver Prado, 2008. 
panoamericano, recordando los intentos de mediación española en el conflicto del Chaco entre Bolivia y Paraguay (1932-35).

Por el contrario, en Los españoles en Rosario de Santa Fe se sitúa el acento en los pormenores positivos de la aportación de los prohombres pasados y presentes de la colonia inmigrante española al progreso económico de la ciudad de Rosario. De ahí la relevante atención otorgada a Casado de Alisal, así como a la intervención del notable español de Buenos Aires y republicano de pro Rafael Calzada -abogado de Casado en la capital federal, y fundador del Barrio Calzada en la primera ciudad (1909), además de donante de los terrenos para la construcción del Hospital Español de Rosario en 1907, y de la Escuela de Artes y Oficios de la Infancia Desvalida en 1917- y otros españoles en las gestiones y licitaciones para la construcción del puerto de Rosario; también se recuerda a los inmigrantes que fundaron talleres de carpintería, fábricas de tabacos, de licores o de negocios de exportación. Se intenta así negar que la hispanofobia más o menos residual, que según Miragaya y Solanes seguiría orientando de modo esporádico algunas publicaciones rosarinas, posea un sustento objetivo o siquiera verosímil. Por el contrario, los autores insisten en una serie de argumentos muy similares a los utilizados por las colectividades de inmigrantes hispánicos en Buenos Aires para legitimar su presencia y concurso al país. Unos eran aplicables a la mayoría de los inmigrantes: el amor al trabajo, la constancia y la prudencia. Otros, sin embargo, redundaban en lo anterior pero le añadían un matiz típicamente hispánico: el español sería, además, tan próximo cultural e históricamente al pueblo argentino que «el español en la Argentina es argentino y en España es español», razón por la que el inmigrante ibérico tendría «la particularidad de unir sus esfuerzos en la construcción psicológica y moral del pueblo». El español, por lo tanto, era un inmigrante sólo a medias, pues su identificación con la cultura argentina a través del idioma y la Historia le facilitaría sobremanera su proceso de integración en el país.

Todas esas estrategias discursivas habían sido ampliamente utilizadas por los intelectuales hispanófilos, quienes desde principios del siglo XX habían comenzado a revalorizar el aporte cultural y humano de los inmigrantes hispánicos, frente al peligro de «italianización» o «extranjerización» de la Argentina a manos de poblaciones inmigrantes «exóticas». Y sólo encontraban un pequeño escollo dialéctico, que los autores de Los españoles en Rosario de Santa $\mathrm{Fe}$ tampoco eluden: el hecho de que la baja condición social de buena parte de los inmigrantes arribados desde 1890 hacía proliferar en la esfera pública argentina, tanto en la prensa como en el teatro popular, los chistes y las revistas ilustradas -desde las porteñas Fray Mocho y Caras y Caretas hasta la rosarina Monos y Monadas - toda una serie de estereotipos minusvalorativos y a veces despectivos contra los inmigrantes españoles, en particular hacia 
los gallegos, que tenían un hondo poso en el imaginario popular desde los tiempos anteriores a la independencia ${ }^{19}$.

El problema, empero, consistía en que la propia élite inmigrante compartía una parte importante de esos estereotipos, y consideraba además a los inmigrantes de baja condición, poco «seleccionados» y formados en la patria de origen para emprender la aventura transoceánica, una doble amenaza, tanto para el prestigio social de los inmigrantes españoles ya establecidos y triunfantes en la Argentina, como para el buen nombre de la patria en general. El conservador reaccionario - y antiguo embajador en la Argentina de la dictadura de Primo de Rivera entre 1928 y 1930 - Ramiro de Maeztu, había vindicado precisamente un año antes (1934), en su obra Defensa de la Hispanidad, a esos inmigrantes analfabetos, poco cualificados y de origen rural, como auténticos depositarios de la tradición hispánica, al estar presente en ellos un poso de educación consuetudinaria y de sentimiento religioso que definirían al buen español ${ }^{20}$. Pero no era ésta la tónica entre la colectividad inmigrante española ya asentada. Miragaya y Solanes optan aquí por la defensa del carácter humilde, trabajador, emprendedor y ahorrativo de esos inmigrantes, que pese a su «indumentaria poco 'chic'» y su «franqueza ruda» que los hacía blanco de burlas e invectivas, también contribuían al progreso argentino. La «delicadeza de corazón» de esos mismos emigrantes, y sobre todo los "gérmenes de civilización congénitos» hacían el resto. En el fondo, se trataba una vez más de la transformación del estereotipo según un molde invertido, mediante la conversión de sus rasgos arquetípicos más negativos en cualidades. Una estrategia argumental perfectamente apreciable en la publicística generada por la élite inmigrante de los diversos colectivos ibéricos inmigrados en la Argentina, en particular de los gallegos, a lo largo del primer tercio del siglo $\mathrm{XX}^{21}$.

Los españoles en Rosario de Santa Fe constituyó un ejemplo un tanto epigonal del tipo de apologías que en la época de la inmigración masiva fueron características de las principales comunidades inmigrantes. Aún vendrían más, y se sumarían a los libros de oro y a las ediciones conmemorativas de asociaciones, círculos y clubes de inmigrantes. La obra de Miragaya y Solanes no sólo pretende ser una recopilación de hechos y figuras acerca de la presencia española en Rosario de Santa Fe desde los tiempos coloniales. Contiene también elementos de un metarrelato, implícito en ocasiones y explícito otras veces, acerca de la visión que una colectividad de inmigrantes, y sus élites dirigentes, querían dar acerca de su contribución al país que los había aco-

\footnotetext{
19 Núñez Seixas, 2002: 27-100; 2013.

20 Maeztu, 1934: 132-34.

${ }^{21}$ Núñez Seixas, 2002: 157-70.
} 
gido y a cuya evolución coadyuvaron, así como sobre la valía del aporte de esa comunidad inmigrante, y su posición dentro de la escala de valores de la sociedad de recepción. En este sentido, es también exponente de una forma de escribir la historia de las comunidades inmigrantes que no por superada por el enfoque analítico y profesional de la historiografía deja de poseer una gran capacidad evocativa, de un tiempo y un lugar.

\section{BiBLIOGRAFÍA}

Álvarez Gila, Óscar, "Los inicios del nacionalismo vasco en América. El Centro Zazpirak Bat de Rosario (Argentina)", Sancho el Sabio, 12 (Vitoria, 2000): 153-76.

Ascolani, Adrián A., Villa Casilda. Historia del optimismo urbanizador (1870-1907), Casilda, Eds. Platino, 1992.

Bernabeu Albert, Salvador, "Los americanistas y el pasado de América. Tendencias e instituciones en vísperas de la Guerra Civil", Revista de Indias, LXVII/239 (Madrid, 2007): 251-82.

Biagini, Hugo, Intelectuales y políticos españoles a comienzos de la inmigración masiva, Buenos Aires, Cedeal, 1995.

Da Orden, M. ${ }^{a}$ Liliana, Inmigración española, familia y movilidad social en la Argentina moderna. Una mirada desde Mar del Plata (1890-1930), Buenos Aires, Biblos, 2005.

Dalla Corte, Gabriela, Lealtades firmes. Redes de sociabilidad y empresas: la "Carlos Casado S. A." entre la Argentina y el Chaco paraguayo (1860-1940), Madrid, CSIC, 2009.

De Cristóforis, Nadia Andrea, Proa al Plata: Las migraciones de gallegos y asturianos a Buenos Aires (fines del siglo XVIII y comienzos del XIX), Madrid, CSIC, 2008.

De Cristóforis, Nadia Andrea, Bajo la Cruz del Sur: Gallegos y asturianos en Buenos Aires (1820-1870), A Coruña, Fundación Barrié de la Maza, 2009.

De Cristóforis, Nadia Andrea, y Fernández, Alejandro E. (eds.), Las migraciones españolas a la Argentina: Variaciones regionales (siglos XIX y XX), Buenos Aires, Biblos, 2008.

De Marco, Miguel Ángel, Argentinos y españoles, Rosario, Fundación C. C. Parque de España, 1988.

De Marco, Miguel Ángel, Carlos Casado del Alisal y el progreso argentino, Rosario, Instituto Argentino de Cultura Hispánica, 1993.

Devoto, Fernando, Historia de la inmigración en la Argentina moderna, Buenos Aires, Sudamericana, 2003. 
Duarte, Ángel, La República del emigrante. La cultura política de los españoles en Argentina (1875-1910), Lleida, Milenio, 1998.

Duarte, Ángel, "Republicanos, emigrados y patriotas. Exilio y patriotismo español en la Argentina en el tránsito del siglo XIX al XX”, Ayer, 47 (Madrid, 2002): 57-80.

Duarte, Ángel, “J. Daniel Infante: El castellano diáfano, el republicano perplejo", en Marcela García Sebastiani (ed.), Patriotas entre naciones. Élites emigrantes españolas en Argentina, Madrid, Editorial Complutense, 2010: 65-81.

Farías, Ruy (ed.), Buenos Aires Gallega: Inmigración, pasado y presente, Buenos Aires, Gobierno de la Ciudad Autónoma de Buenos Aires, 2007.

Fernández, Alejandro E. y Moya, José C. (eds.), La inmigración española en la Argentina, Buenos Aires, Biblos, 1999.

Fernández, Sandra R. y Dalla Corte, Gabriela (eds.), Sobre viajeros, intelectuales y empresarios catalanes en Argentina, Tarragona, s. ed. [Bou Impressors], 1998.

Fernández, Sandra R. y Oliver, M. Rosa (coord.), Catálogo Fotográfico del Club Español de Rosario 1882-1940, Rosario, Prohistoria, 2004.

Frid, Carina, "Más allá del crisol. Matrimonios, estrategias familiares y redes sociales en dos generaciones de italianos y españoles (Rosario, 1895-1925)", Estudios Migratorios Latinoamericanos, 28 (Buenos Aires, 1994): 481-520.

Frid, Carina, "A Imigraçâo Espanhola na Argentina (1880-1930)", Boris Fausto (coord.), Fazer a América. A Imigraçâo en Massa para a América Latina, Sâo Paulo, Edusp, 1999: 93-126.

Irianni, Marcelino, Historia de los vascos en la Argentina, Buenos Aires, Biblos, 2010.

Jofre Cabello, Ana, Así emigraron los baleares a la Argentina, Palma de Mallorca, Govern Balear, 2001.

Lanciotti, Norma S., "La movilidad espacial de los inmigrantes en las ciudades portuarias argentinas. El caso de Rosario, 1880-1814”, Estudios Migratorios Latinoamericanos, 51 (Buenos Aires, 2003): 385-415.

Maeztu, Ramiro de, Defensa de la Hispanidad, Madrid, Gráfica Universal, 1934.

Marcilhacy, David, Raza hispana: Hispanoamericanismo e imaginario nacional en la España de la Restauración, Madrid, CEPC, 2010.

Moya, José C., Primos y extranjeros. La inmigración española en Buenos Aires, 1850-1930, Buenos Aires, Emecé, 2004 [Berkeley 1998].

Núñez Seixas, Xosé M. (ed.), La Galicia Austral. La inmigración gallega en la Argentina, Buenos Aires: Biblos, 2001a.

Núñez Seixas, Xosé M., "Leadership ethnique, exil politique et ethnonationalisme chez les collectivités ibériques en Amérique Latine (1880-1960)", F. Devoto y P. González-Bernaldo (eds.), Émigration politique. Une perspective comparée. Italiens 
et Espagnols en Argentine et en France (XIXe - Xxe siècles), París, L'Harmattan, 2001b: 263-94.

Núñez Seixas, Xosé M., O inmigrante imaxinario. Estereotipos, representacións e identidades dos galegos na Arxentina, 1860-1940, Santiago de Compostela, USC, 2002.

Núñez Seixas, Xosé M., "Deconstruyendo la parroquia glocal: Asociacionismo, redes sociales y hábitat urbano de los inmigrantes gallegos en Buenos Aires (19001930)", Historia Social, 70 (Valencia, 2011): 107-33.

Núñez Seixas, Xosé M., Icônes littéraires et stéréotypes sociaux. L'image des immigrants galiciens en Argentine (1800-1960), Besançon, PUFC, 2013.

Núñez Seixas, Xosé M. y Soutelo, Raúl, As cartas do destino: Unha familia galega entre dous mundos, 1919-1971, Vigo, Galaxia, 2005.

Prado, Gustavo H., Rafael Altamira en América (1898-1910): Historia e Historiografía del proyecto americanista de la Universidad de Oviedo, Madrid, CSIC, 2008.

Romero, Ana Leonor, "La política del patriotismo. La conformación de la Asociación Patriótica Española, (1896-1898)", Estudios Migratorios Latinoamericanos, 64 (Buenos Aires, 2007): 454-487.

Sánchez, Santiago Javier, "La intendencia de Daniel Infante en Rosario (1912-1913): Las paradojas de un socialista español”, Historia Regional, 23 (2005): 87-101.

Sánchez Alonso, Blanca, La inmigración española en Argentina. Siglos XIX y XX, Colombres, Archivo de Indianos, 1992.

Sepúlveda, Isidro, El sueño de la Madre Patria. Hispanoamericanismo y nacionalismo, Madrid, Marcial Pons/Fundación Carolina, 2005.

Sonzogni, Elida, y Dalla Corte, Gabriela (comps.), Intelectuales rosarinos entre dos siglos: Serafin, Clemente y Juan Álvarez. Identidad local y esfera pública, Rosario, Manuel Suárez Ed., 2002.

Tabanera García, Nuria, Ilusiones y desencuentros. La acción diplomática republicana en Hispanoamérica (1931-39), Madrid, CEDEAL, 1996.

Tarcus, Horacio (dir.), Diccionario biográfico de la izquierda argentina. De los anarquistas a la "Nueva Izquierda” (1870-1976), Buenos Aires, Emecé, 2007.

Valero Juan, E. M", Rafael Altamira y la "reconquista” espiritual de América, Alicante, Universidad de Alicante, 2003.

Vera de Flachs, $\mathrm{M}^{\mathrm{a}}$ Carmen, Españoles en Argentina. Redes sociales e inserción ocupacional. Córdoba, 1840-1930, Córdoba, Ediciones del Copista, 1996.

Fecha de recepción: 8 de febrero de 2013.

Fecha de aceptación: 7 de junio de 2013. 